\title{
AQUISIÇÃO DO SISTEMA FONOLÓGICO DO PORTUGUÊS: CORRELAÇÕES OPOSITIVAS, TRAÇOS E HIERARQUIZAÇÃO
}

\author{
WILMAR DA ROCHA D'ANGELIS \\ (UNICAMP)
}

Quando uma criança está adquirindo a fonologia de uma língua, que tipo de operações mentais estaria executando? Esta é a questão realmente crucial para colocarse à prova as teorias fonológicas. E estou convencido de que essa é a questão que merece ser focalizada para produzirmos uma teoria fonológica inovadora. O problema, nada insignificante, é justamente, como saber que tipo de operações uma criança realiza na aquisição da fonologia? Essa não será a questão central do presente texto, mas é com isso, em última análise, que seu autor está preocupado e é para esse tipo de investigação que ele quer chamar a atenção do leitor ${ }^{1}$.

As sugestões que se encontram no texto a respeito dos "traços mínimos" e da forma de sua complexificação foram construídas a partir da perspectiva de inspiração construtivista-interacionista com que encaro os fatos de aquisição da linguagem, entendendo interação como: (i) as relações da criança com o meio social (falante/ouvinte, na aquisição de línguas orais, ou sinalizador/vidente ${ }^{2}$, na aquisição de línguas de sinais), que implicam agir nele ou sobre ele e ser 'agida' (e significada) por ele $^{3}$; (ii) as relações da criança com seu próprio 'suporte' de manipulação da linguagem (o aparelho fonador, nas crianças ouvintes; as mãos e a face, nas crianças surdas), e (iii)

'Remeto, no entanto, a um texto valioso, ainda que não ocupado com fonologia, em que Cláudia de Lemos (1997) contrapõe diferentes perspectivas a respeito do 'trabalho' da criança no processo de 'aquisição'.

2 É difícil escolher as palavras nessa área em que não se consagraram termos equivalentes. Surdo faz contraposição a Ouvinte na perspectiva identitária. Mas, enquanto as habilidades/possibilidades linguísticas de um Onvinte podem ser expressas por essa própria palavra (ouvinte) somada à que expressa a possibilidade da comunicação oral (falamte), as de um Surdo não podem ser expressas pela surdez. De fato, as habilidades/possibilidades equivalentes, nas pessoas surdas, àquelas referidas para pessoas outintes, seriam o fato de poder sinalizar (em oposição a falante: o que fala ou pode falar) e o fato de poder usar a visão como canal de recepção da linguagem de outros (em oposição a ouvinte: o que ouve ou pode ouvir). Embora a forma participial vidente se empregue. em Português, mais comumente para expressar outro sentido (o de pessoa "paranormal', capaz de prever fatos futuros), o sentido de "aquele que vê" ou "o que pode ver" é legítimo e é usado, inclusive, exatamente como o termo ouvinte se emprega em oposição a surdo, para distinguir vidente em relação a c'ego.

3 Aqui também contemplando a linha desenvolvida por Cláudia de Lemos, de cujo trabalho mencionado em nota anterior reproduzo as linhas finais: "...it becomes possible to assign to adult-child interaction a more important role in language aquisition as the loctus of linguistic and discourse functioning where structuring relations take place and the infant starts its journey as a speaker" (De Lemos 1997:1213). 
as relações da criança com a língua em si mesma. Ainda que assumindo o fato óbvio de que a linguagem é da ordem do simbólico, assumo a hipótese de que o simbólico se constrói a partir de um material 'bruto' (gestos articulatórios e seus efeitos acústicos/visuais e comportamentais, em fonologia) e do potencial brutal de cognição da mente humana (seja lá o que for isso, e que a psicologia nos socorra). Tudo isso levaria a sugerir que, antes de 'traços' mínimos a criança aprende a dominar 'gestos' básicos que, quando associados por ela a distinções opositivas significativas, tornam-se 'traços', que são gestos, conjuntos de gestos ou efeitos simbolizados. Isso explica porque, para mim, os dados da investigação fonética são tão relevantes quanto os estudos longitudinais e comparativos de aquisição da linguagem. Mas isso, como está dito, será apenas esboçado nesse trabalho.

É importante dizer que este pequeno texto dialoga com outros três: basicamente com o trabalho de Helena Mota (1997), mas também com um texto de G. Rangel, e um terceiro trabalho, de Cátia Fronza, todos eles publicados em Letras de Hoje ${ }^{5}$. E, finalmente, confessar que não tenho, com esse trabalho, a pretensão de polemizar, efetivamente. Tampouco sinto-me completamente à vontade para falar de fatos de aquisição, área $\mathrm{em}$ que não realizo pesquisas diretamente e na qual sou 'visitante'. Minha única intenção é sugerir - do lugar de minhas pesquisas em fonologia (e na vertente das geometrias de traços), de uma perspectiva que busca aproximar ao máximo fonologia da pesquisa em fonética - algumas linhas de investigação que podem contribuir para a discussão dos especialistas na área, ainda que possa resultar apenas na condenação de minhas ousadias e, quem sabe, heresias.

\section{CHEGANDO PARA A AQUISIÇÃo}

Escreve Mota (1997:31-2) que "a criança chega para a tarefa de aquisição fonológica com uma estrutura representacional básica que é dada na GU. Esta geometria básica é composta apenas por traços não-marcados e compreende um nó de Raiz com os traços [ \pm soante, - vocóide, -aproximante] já especificados para as consoantes; um nó de Laringe, com os traços [-voz] para os segmentos [-soante] $e$ [+voz] para os [+soante]; um nó de Cavidade Oral ramificado em [-contínuo] e Ponto de C com os traços [coronal] e [labial]. Esta representação geométrica básica faz com que os inventários fonológicos iniciais sejam formados pelos sons / $p, t, m, n /$ "

Mas será que é esta mesmo a 'muda de árvore' que a criança recebe de GU? ${ }^{6}$ Quero começar sugerindo 'podas'.

${ }^{4}$ Remeto a discussão da questão a Albano (1990), que em muitos aspectos inspira este trabalho.

${ }^{5}$ MOTA, H.B. (1997). Aquisição segmental do Português: um modelo implicacional de complexidade de traşos. RANGEL, G.A (1998). Os diferentes caminhos percorridos na aquisição da fonologia do português. FRONZA, Cátia de A. (1998). O dominio do traço [tsonoro] e do nó ponto de C na aquisiçũo normal e com desvios da fonologia do português brasileiro. Ver Referências Bibliográficas.

${ }^{6}$ No limite eu argumentaria, mas não o farei aqui, contra essa herança arbórea (mas não contra sua existência, construída que é), propugnando um processo de (auto-) organização interna (mas nunca alheio ao externo) que tem no gesto articulatório a base de seu desenvolvimento, mas não seu ápice; a organização 24 
Antes, porém, apresento uma premissa importante: quando um traço binário está presente, ou seja, quando um traço binário é adquirido, isso significa que os dois valores que ele pode assumir ( $+\mathrm{e}-$ ) estão presentes no sistema, isto é, foram adquiridos. $\mathrm{O}$ pressuposto que essa perspectiva encerra é o de que o sistema fonológico de fato constrói-se pelo estabelecimento de correlações, ou seja, pela fixação de valores contrastivos, na mais 'pura' noção saussureana de valor, que embasou a perspectiva estrutural-funcionalista da língua como sistema. Isso não é muito diferente, no caso de traços não-binários (que não cabiam em SPE, mas que hoje são de aceitação geral nas fonologias não-lineares, como é o caso, por exemplo, dos articuladores labial, coronal e dorsal). A presença ativa (leia-se, fonologicamente distintiva) de um articulador, implica na percepção de sua presença ou ausência (o que seria o caso de SP para Nasal ${ }^{7}$ ) ou na percepção de sua presença versus a presença de um articulador concorrente. Assim, por exemplo, se um sistema já possui o traço coronal, significa que já pode reconhecer igualmente um traço dorsal e um traço labial. A recíproca, no entanto, não é verdadeira, ou seja, a presença de um gesto labial pode não ser ainda a indicação da presença de contraste, uma vez que um sistema (de criança em aquisição) poderia possuir o traço binário [ \pm aproximante] e realizar seu valor negativo (não-aproximante) pela forma mais óbvia e de mais fácil articulação, ou seja, labial, sem que isso implicasse oposição a outro ponto de articulação. De fato, sugerirei que a primeira distinção de articulador se dá entre lábio e língua, construindo-se as distinções dorsal, coronal anterior e coronal posterior em outro momento. ${ }^{8}$

Vamos às 'podas', então.

Em primeiro lugar, uma longa tradição fonológica tem reconhecido que vozeamento espontâneo é de natureza diferente do vozeamento que se realiza em obstruintes. Chomsky \& Halle (1968) registraram isso, até como defesa do traço [soante] (sonorant), mas mantiveram a redundância contraditória: todo elemento soante é, também, [+voz]. Na literatura recente, em fonologia, recuperamos essa discussão (ainda que importantes autores na vertente das geometrias de traços, como Clements, a tenham praticamente ignorado) e há fortes evidências sendo trazidas em favor de distinguir-se, efetivamente, voz soante de voz laríngea.

Ainda que todo vozeamento, espontâneo ou não, se dê pela vibração das cordas vocais, a denominação voz laríngea quer apontar para o fato que, no caso do vozeamento não espontâneo, temos a laringe (ou as cordas vocais) como articuladores ativos, isto é, selecionados pela fonologia da língua para operar na produção de

simbólica é que dá origem aos traços, que implica em 'gestar' correlações opositivas na interação das práticas próprias de produção lingüística com o 'meio falante' circundante (modelo que vale, igualmente, para línguas de sinais). A inspiração em Albano (1990) pode ser apontada também aqui. Por exemplo, na seguinte passagem: "Tocar de ouvido significa, pois, confeccionar um símbolo com recursos concretos ou quase concretos (...) Cabe, além disso, notar que, no caso de o vocabulário inicial se desenvolver viso-manualmente, 'fala' se poderia automaticamente substituir por 'gesto significativo', ficando a sensorimotricidade lingüistica entendida nos mesmos termos" (Albano 1990:20).

${ }^{7} \mathrm{SP}=$ Soft Palate (Palato Mole). É o articulador proposto por Sagey (1986). Ver a respeito, D'Angelis 1998:81-84, 222ss.

${ }^{8}$ Veja-se que a distinção 'secundária' [tanterior], sob [coronal]. é ilustrativa desse tipo de aquisição paulatina. isto é. do refinamento pelo qual se vai constituindo, na criança, o controle dos articuladores. 
diferenças significativas entre sons ${ }^{9}$. A idéia básica (que deriva de uma velha lição de Trubetzkoy [1939] 1969) é que um articulador é parte da representação fonológica em uma língua, apenas se ele participa de uma oposição (ou correlação opositiva) significativa. De outro modo, ele pode até ser acionado e produzir efeitos acústicos perceptíveis, mas apenas como "reflexo" ou suporte para uma correlação opositiva que não se refere a ele. É o caso, por exemplo, do véu palatino, como o sugeriu Piggott (1992) e suponho ter demonstrado em outro lugar (D'Angelis 1998). A simples presença de nasalidade em um segmento não significa que o traço fonológico nasal esteja acionado ou esteja operando. Basta que um sistema fonológico estabeleça uma oposição entre descontínuas obstruintes e descontínuas soantes para que, no caso das últimas, o falante seja obrigado a abaixar o véu palatino, como único recurso de garantir soanticidade (ou seja, vozeamento espontâneo). Em outras palavras, uma língua pode opor $/ \mathrm{p}, \mathrm{t} / \mathrm{a} / \mathrm{m}, \mathrm{n} /$ pelo traço [ \pm soante], e o traço [nasal] será, aí, mero recurso de implementação fonética. Nesse caso, o articulador do traço [nasal], ou seja, SP (soft palate $=$ véu palatino) na sugestão de Sagey (1986), não opera fonologicamente, ou seja, não participa de correlação opositiva. Assim como o caso da nasal, o mesmo temos para o caso do traço [ \pm voz], produzido na Laringe, na presença da oposição obstruinte $\mathrm{x}$ soante. Para esta correlação opositiva, ainda que as cordas vibrem (aparentando haver [+voz]), elas o fazem em função da configuração produzida para se obter soanticidade que contraste com obstrução. Ou seja, não há participação de [ $\pm v o z]$ como oposição distintiva, ainda que a percepção acústica seja de não-vozeamento nas obstruintes e de vozeamento nas soantes.

Sendo assim, sugiro a poda do nó de Laringe (com o traço [ \pm voz]) da arvorezinha fornecida pela GU às inocentes crianças que chegam para a tarefa de aquisição fonológica. Não o faço, porém, para atender as especificidades da língua portuguesa. $\mathrm{O}$ faço pela compreensão que quero defender da organização (universal) que a criança vai construindo do sistema de traços e de suas relaçōes ao longo do processo de aquisição da fonologia.

A análise fonológica do Português que assumo aqui, parte da interpretação de Mattoso Câmara Ir. ${ }^{10}$, segundo a qual a oposição central básica entre as consoantes do sistema fonológico do Português se dá entre "os fonemas consonânticos puros, plosivos e fricativos" e o conjunto das "nasais, laterais e vibrantes" que se caracterizam "por uma combinação do consonântico com o vocálico (sonântico)" (cf. Câmara Jr. [1970] 1991:49). Em outras palavras: obstruintes ( $\mathrm{p}, \mathrm{b}, \mathrm{t}, \mathrm{d}, \mathrm{k}, \mathrm{g}, \mathrm{f}, \mathrm{v}, \mathrm{s}, \mathrm{z}, \int, 3$ ) x soantes ( $\mathrm{m}, \mathrm{n}, \mathrm{n}, \mathrm{l}, \kappa, \mathrm{f}, \mathrm{r})^{11}$. Essa interpretação da oposição central obstruintes $\mathrm{x}$ soantes é

${ }^{9}$ Normalmente, em contextos onde isso é menos simples: vozear em contexto de total obstrução no trato vocal/nasal, ou não-vozear com o trato desobstruído.

${ }^{10}$ Não por acaso, adepto da fonologia do Círculo Lingüístico de Praga, $e$ "talvez o único em nosso País", como sugeriu Yonne Leite (1990:35).

11 Esta é a proposição de Mattoso Câmara para o Português Brasileiro (com base no dialeto carioca) nos anos 50 e 60 (a versão básica de sua análise está em sua tese de doutorado, de 1949), ou seja, algo entre 40 e 50 anos atrás. Considerando que sua análise tomava por base a fala adulta (o próprio Mattoso tinha 45 anos ao doutorar-se em lingüística e não discute fenômenos de aquisição da linguagem - como, aliás, bem 26 
também a minha análise para o Português brasileiro do final do século XX, apoiado em evidências que me são sugeridas exatamente pelo modelo que proponho para as relações hierárquicas dos traços distintivos (que, em parte, expus em D’Angelis 1998).

Sugiro que as primeiras distinções que a criança reconhece e pode produzir equivalem, grosso modo, a:

1. configurar o trato, de modo a diferenciar sons, sem obstruí-lo $X \underline{\text { obstruir o }}$ trato para produzir sons diferentes

\section{2. produzir vozeamento espontâneo X impedir o vozeamento espontâneo}

O caso (1) opõe, nas produções iniciais da aquisição, sons aproximantes a nãoaproximantes, o que corresponde, nesse momento da aquisição, a vogais $\mathrm{x}$ consoantes. Em outras palavras, não é preciso estabelecer, aqui, a ocorrência de uma distinção fonológica do tipo vocóide $\mathrm{x}$ não-vocóide. A distinção que a criança estabelece, com base na percepção acústica, e que produz em suas emissões, se dá entre aproximantes $\mathrm{e}$ não-aproximantes. ${ }^{12}$

O caso (2) opõe soantes a não-soantes, o que significa, colocar de um lado as aproximantes todas e as não-aproximantes que apresentem o véu palatino abaixado (resultando em consoantes "nasais") e, de outro lado, as não-aproximantes para as quais se fecha o véu palatino para impedir que vozeiem.

Os resultados das combinações dos dois traços básicos sugeridos pode ser visto abaixo:

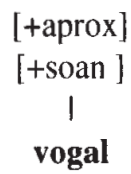

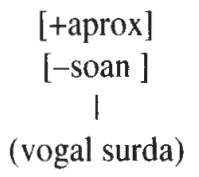

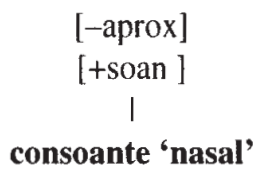

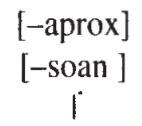

consoante plosiva

observou Miranda 1998:124), e considerando o caráter extremamente jovem da população brasileira, podemos estimar que, entre o Português que falamos hoje e aquele magistralmente descrito por Mattoso, nos separam 3 ou 4 gerações! No caso das vibrantes, especificamente, uma mudança parece ter se consolidado nesse período (que aparecia como variação na análise de Câmara Jr.). E talvez estejamos prestes a assistir a consolidação de outra mudança nas líquidas, envolvendo as realizações pré e pós-vocálicas de / I/ .

${ }^{12}$ Por que a realização de não-(lproximante é, para a criança, uma oclusão e não uma fricção? Essa é uma questão pertinente. Sugiro que ela não trabalha, aí, com a distinção [ \pm contínuo], o que me faz recusar a idéia de que esteja implementando o traço [-contínuo] como não-marcado. Estou propondo que [-contínuo] só passa a ser 'compreendido' como traço não-marcado da oposição [ \pm contínuo] quando a criança adquire essa nova correlação opositiva, percebendo que há uma forma diferente daquela com que ela vem produzindo toda e qualquer não-soante, ou seja, que pode haver uma obstrução parcial e intermitente (e não apenas obstrução total e pontual ou momentânea), e que opor um tipo ao outro é significativo na língua. Mas. conquanto não seja ainda um traço de valor não-marcado (por não integrar o quadro de oposições fonológicas do sistema da criança até entâo) o gesto de obstrução total, que correponde a [-contínuo], é a forma de implementação default de não-aproximantes. Por que? Para mim, essa é uma resposta que vem da fonética. e não da fonologia! Sustentar uma obstrução aproximada no trato exige um controle ou coordenação mais fina do que produzir uma obstrução completa seguindo-a de uma soltura instantânea. 
A combinação [+aprox, -soan] daria, ao que parece, vogais surdas. Contra a produção desse resultado, militam duas circunstâncias: (i) a criança não encontra essa combinação acústica nas produções que ouve no ambiente, de modo que não seria estimulada a produzi-las; (ii) o impedimento do vozeamento espontâneo, quando se dá uma configuração aproximante no trato oral, exige um controle que corresponde ao vozeamento laríngeo, ou seja, ao uso ativo das cordas vocais em uma correlação [ \pm voz], o que não está disponível para a criança nesse primeiro estágio ${ }^{13}$.

Sugiro também a 'poda' do traço [contínuo] (referindo-me à proposta de Mota, com que iniciei essa discussão, e não a um 'desligamento' de estruturas previamente dadas). Considero que [ \pm contínuo] não está ainda operante porque esse traço é adquirido para opor plosivas a fricativas, e esse é, reconhecidamente, um passo posterior, no Português, à aquisição das demais obstruintes, ainda não-marcadas para essa ulterior oposição. ${ }^{14}$

Observe-se, por exemplo, o inventário fonológico inicial dos sujeitos da pesquisa de Rangel (1998:134): das quatro crianças, a única que possuía uma fricativa (não por acaso, /s/) era a que já possuía, em seu inventário, todas as plosivas da língua: / p , b, t, $\mathrm{d}, \mathrm{k}, \mathrm{g} /$. No trabalho de Mota, a síntese das relações implicacionais de marcação mostra a aquisição das primeiras fricativas (não por acaso, labiais e coronais anteriores) somente depois da aquisição das plosivas / p, t, b, d, k /. A única plosiva que seria adquirida depois de fricativas, a partir dos seus dados, seria / g / (Mota 1997:31). Se atentarmos, porém, a outra sistematização da mesma autora, a saber, a que, resumindo suas observações, hierarquiza os sons ausentes nos inventários dos 25 sujeitos pesquisados ("crianças com desvios fonológicos"), encontraremos / p, t, m, n, ñ / em todos os falantes, / d / ausente em um deles, / b / ausente em dois, / k / ausente em três e /g / ausente em cinco falantes. As fricativas, porém, superam esses números. Em sete falantes estão ausentes / v , z /, em oito falantes não se encontra / f /, em nove falantes não se encontra / s / e em mais de dez falantes não se observou $/ \int / \mathrm{nem} / 3 /$ (Mota

${ }^{13}$ Não discutirei aqui o 'ajuste' necessário entre essa proposta (que aponta para nó Raiz definido por dois traços, um dos quais, soante) e a proposta de D'Angelis 1998, em que apresento o traço SV (vozectmento) espontâneo) como subordinado, mas não preso ao nó Raiz. Em princípio, minhas soluções para assimilação $e$ harmonização nasal apresentadas naquele trabalho não dependem de espalhamento de SV (ao contrário, apontam para espalhamento de $\mathrm{SP}=$ soft pulate), a não ser marginalmente, ao justificar certos ajustes pelo partilhamento (fusão, por imposição de OCP) de SV em segmentos adjacentes (cf. D'Angelis 1998, vol..II:236-243). Não é absurdo sugerir, como linha de investigação, que o parâmetro universal inicial seja ajustado, depois, na aquisição, caso a língua tenha alçado o traço soante a componente relevante de seu sistema fonológico final, o que pode lhe dar (ou exigir) uma autonomia em relação ao nó Raiz.

14 Registro que a proposição de Mota da presença de [-contínuo] como un traço não-marcado na 'estrutura representacional básica que é dada na $G U^{\prime \prime}$ atende corretamente a um dado observacional: o fato das crianças, naquela fase, não produzirem consoantes contínuas (fricativas), mas apenas descontínuas (plosivas e soantes nasais). Minha abordagem (apontada nas minhas premissas) recusa, porém, a interpretação dada ao fato, e propõe que a característica descontínua das primeiras consoantes não deve ser interpretada como domínio de um valor não-marcado de um traço. Como se viu, sugeri que o que está em jogo, nessa fase, é outra oposição, aquela entre cuproximame e não-ciproximante (que, no meu modelo, não é meramente classificatória, mas corresponde efetivamente a determinados gestos articulatórios), e a forma de realizar o valor negativo é, naquele momento, a obstrução pontual com soltura instantânea. 
1997:27). Isso pode ser contra-argumento à escala 'implicacional' sugerida pela autora $^{15}$.

A proposição de que o traço [contínuo] estaria disponível apenas com seu valor não-marcado (ou seja, apenas [-contínuo] estaria na 'árvore primeva') contraria, por fim, a premissa segundo a qual um traço é adquirido para opor 'qualidades' (e, portanto, valores opostos em traços binários). Em minha proposta, a indicação de [-aproximante] basta à produção de uma obstruinte que, para a primeira fase de 'controle' da criança sobre seu aparelho fonador, significa obstruir completamente e soltar instantâneamente.

Dos traços sugeridos por Mota para a árvore herdada da GU, resta falar sobre Cavidade Oral e Pontos de C (isto é, ponto de articulação de consoante). Não vou aterme ao problema da existência ou não de um nó Cavidade Oral. Para Clements \& Hume (1995), inspirados em Clements (1987), Cavidade Oral (CO) abarca os traços de ponto de articulação (Ponto de $C$, sob o qual está Vocálico, sob o qual está Ponto de $V \mathrm{e}$ Abertura) e o traço [contínuo] (para eles, não binário]. Dispensar-me da discussão torna o presente texto mais enxuto, e posso fazê-lo porque já sugeri, acima, que [ \pm contínuo] é adquirido em estágio ulterior da aquisição. ${ }^{16}$

Reporto-me, pois, finalmente, ao problema dos pontos de articulação. Sugiro, com base nos dados de aquisição do Português (mas, também, nas informações sobre universais lingüísticos) que a primeira distinção de ponto, no sistema fonológico da criança, reconhece apenas dois articuladores: lábios e lingua, seja para a produção de aproximantes, seja para não-aproximantes. Isso explica, por exemplo, as oscilações entre [士anterior] (responsáveis, por exemplo, pela chamada "fala de bebê", palatalizando oclusivas, e pelas trocas entre fricativas coronais anteriores e não-

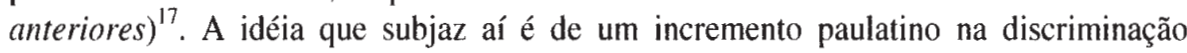
acústica e no controle dos próprios articuladores: ao reconhecer uma primeira distinção

${ }^{15}$ A propósito, os estudos de universais lingüísticos mostram que há línguas do mundo sem fricativas, mas nenhuma, sem plosivas. E, se uma língua tem apenas uma fricativa, essa raramente não será / $\mathrm{s} /$.

16 Entretanto, é oportuno observar que Mota (1997:27) afirma textualmente adotar o modelo representacional de Clements \& Hume, mas em nenhum momento justifica a transformação de [contínuo] em traço binário (onde contraria aqueles autores). Em D'Angelis (1998), entre as observações críticas que dírigi a esta configuração lembrei que, em muitas línguas, a obstrução (contínua ou descontínua) pode ser produzida na região glotal ou faríngea. o que torna sem sentido alocar o traço [continuo] sob um nó Cavidade Oral que não reúne, no caso das línguas em questão, o(s) responsável(is) pela realização do traço.

${ }^{17}$ É bastante ôbvio que a criança possa produzir (e, de fato, produza) sons que ainda não integram uma correlação opositiva. seja por 'equívoco' seja por tentativas iniciais de reconhecimento e controle. O mesmo se pode pensar em relação à aquisição de $2^{\mathrm{a}}$ língua. É previsível, por exemplo, que um falante nativo de Português produza [de] e [det], para 'the' e 'that', do Inglês, e produza [ig] ou [id] para 'in' = ['ifj]']. em Kaingang, porque nos dois casos, a língua alvo realiza distinções que não estão presentes no sistema fonológico com que o sujeito aprendiz opera. Mas ao mesmo tempo, é perfeitamente cabível que, no esforço de descobrir o lugar da diferença que percebe entre sua fala e a do(s) outro(s), e no esforço de produzir algo parecido ao que ouve e que seja diferente do que já costuma produzir, o falante aprendiz da $2^{\mathrm{a}}$ língua produza acertos ocasionais e, igualmente, outros tantos equívocos. A propósito, tratando de aquisição em Português, Cátia Fronza observou, a respeito do inventário fonético dos sujeitos observados, que "não existe. necessuriamente, uma relaçäo direta entre inventário fonético e sistema de fones contrastivos (...) . pois alguns sons estão sendo produzidos efetivamente. mas sua função contrastiva ainda está em aquisição" (Fronza 1998:145). 
entre articulação com os lábios e articulação com a língua, a criança ainda não desenvolveu um controle fino sobre a língua que the permita produzir consoantes distintas com partes específicas dela. Nesse momento, apesar das oscilações possíveis, há pouco mencionadas, o recurso mais simples disponível para obstruir o trato oral com a língua é a parte frontal deste articulador, o que explica a aquisição, em primeiro lugar, das consoantes $/ \mathrm{p} / \mathrm{e} / \mathrm{t} /, / \mathrm{m} / \mathrm{e} / \mathrm{n} /$, antes que apareçam as dorsais e palatais. $\mathrm{O}$ fato, aliás, de que a distinção entre coronais [+anterior] e coronais [-anterior] seja a última a se fazer, no Português, em ponto de articulação (depois de opor labial, coronal anterior e dorsal), é fato que mostra o caráter progressivo desse refinamento no controle dos articuladores $^{18}$. O refinamento, aliás, também se dá na percepção da diferença (uma vez que, para as coisas que estão dentro da boca, a criança só tem acesso pelo recurso auditivo, sendo de muito pouca importância, nesse caso, a evidência visual).

Num momento seguinte, portanto, é que a criança passará a reconhecer diferenças nos sons 'internamente' produzidos, e desenvolverá o controle que lhe permita distinguir, na língua, duas regiões distintas de articulação: coroa e dorso. Nesse momento, então, em seu sistema fonológico a criança substitui a correlação opositiva lábios x língua, por uma nova correlação, tripartida: labial, coronal, dorsal. Como mostram os dados já mencionados, é somente depois de firmada essa correlação de pontos que a criança estará apta ou atenta à correlação entre contínuas e descontínuas. Mas, é preciso voltar um pouco atrás, quando surge a percepção, para a criança em aquisição do Português, da oposição [ \pm voz].

Os dados mostram que essa correlação (vozeado x desvozeado) surge antes da mudança na primeira correlação opositiva de pontos articuladores. Ou seja, quando a criança ainda opera apenas com a oposição lábios x lingua ela tem sua atenção despertada para a distinção entre surdas e sonoras. Aqui, tratamos do caso particular das línguas que, como o Português, elegem essa correlação opositiva como significativa. Em línguas onde [ \pm voz] não se constitui numa oposição fonológica, os passos possivelmente serão os indicados acima (incremento da correlação de ponto em um grau e, em seguida, surgimento da oposição [ tcontínuo] $)^{19}$.

Observemos, por um momento, dados de aquisição, em um trabalho que buscou verificar exatamente o controle do traço [ \pm voz] (ou, [ \pm sonoro], como preferiu a pesquisadora a que recorro ${ }^{20}$ ). Cátia Fronza observou dados de 6 crianças, a metade das quais com desenvolvimento fonológico avaliado como normal e a outra metade com "desvios fonológicos evolutivos". Na análise das substituições de fones, registrou as seguintes incidências mais significativas:

${ }^{18}$ E o fato de estabelecer a distinção entre dorsal e coronal e, depois, distinguir coronal não-cınterior de coronal anterior é que faz a criança 'tomar' essa última como valor não-marcado entre os três.

${ }^{19}$ É provável que a relativa independência entre as duas correlações, indicada pelo modo como podem ou não interagir em línguas diferentes, explique porque o surgimento da oposição [ \pm contínuo] ocorra primeirò com o aparecimento de fricativas surdas, mesmo numa língua como o Português onde, àquela altura, a oposição [£voz] já aparece entre as plosivas.

20 A versão, para português, de [voiced/unvoiced] ou de [voice] varia, conforme o autor, para [ \pm vozeado], [ \pm voz] ou [ \pm sonoro]. As escolhas são idiossincráticas. 
(a) Mudanças de [+voz] $\rightarrow$ [-voz]: $\quad b \rightarrow p, d \rightarrow t, g \rightarrow k, v \rightarrow f, z \rightarrow s, \int \rightarrow 3$ ("evidenciadas basicamente no DFE", isto é, no grupo com "desvios fonológicos evolutivos").

(b) Mudanças de [dors] para [cor]: $\mathrm{k} \rightarrow \mathrm{t}, \mathrm{g} \rightarrow \mathrm{d}$ ("verificadas no grupo DFN", isto é, com "desenvolvimento fonológico normal").

(c) Mudanças de [+ant] para [-ant]: $s \rightarrow \int$ e $\mathrm{z} \rightarrow 3$ ("mais sujeitos $\left.D F N "\right)$.

O número de sujeitos da pesquisa, suas diferenças em idade, bem como a origem distinta dos dados ${ }^{21}$, certamente contribuem para relativizar muito alguns dos seus resultados. Ainda assim, os dados parecem mostrar o não domínio do traço [ \pm voz] quando as correlações de ponto labial, coronal e dorsal já parecem bem estabelecidas. As oscilações no grupo fricativo tanto podem indicar que a correlação [ \pm contínuo] se estabeleceu antes de $[ \pm v o z]$, como podem indicar que, uma vez estabelecida essa última correlação em plosivas, é preciso primeiro construir a possibilidade da ocorrência das fricativas para, então sim, estender a elas a correlação de vozeamento.

As substituições representadas em (b), sobretudo por tratarem de crianças com desenvolvimento fonológico avaliado como normal, mostram que a correlação de vozeamento fica bem estabelecida antes que se opere uma complexificação na correlação de Ponto de C (ou seja, enquanto o falante ainda não opera com dorsal $\mathrm{x}$ coronal).

Finalmente, as mudanças em (c) confirmam minha sugestão de que, um segundo passo na complexificação do reconhecimento e controle da correlação ponto de $C$, ocorre pela distinção que se estabelece (após já adquirida a oposição coronal $\mathrm{x}$ dorsal) entre coronal anterior e coronal não-anterior. ${ }^{22}$

Uma conclusão final, a partir dos dados em Fronza (1998), é que a dificuldade no desdobramento do controle de ponto de $C$ está presente, como algo normal, depois que a correlação de vozeamento já se deu ${ }^{23}$. Pela ordem, confirmando minha sugestão: (i) a transposição de velares para alveolares (dorsal $\rightarrow$ coronal), e (ii) a oscilação entre alveolares e palatais. Nesse último caso, os poucos dados de Fronza apontam uma direção sempre de [+ant] para [-ant], fato para o qual a própria pesquisadora chama a atenção, sugerindo que o esperado ou, "o mais comum", seria o oposto (Fronza

${ }^{21}$ Para o primeiro grupo, Fronza usou dados de seu próprio trabalho de coleta; para o segundo grupo, lançou mão de dados do banco "Linguagem da Criança com Desvios Fonológicos", do CEAAL-PUCRS. O grupo dos $D F N$ tinha a idade variando entre um ano e seis meses e um ano e nove meses. Já o grupo dos $D F E$ variou de quatro anos e três meses a 8 anos completos.

22 Dada a sequiência que estou sugerindo para a construção do conjunto de correlações em ponto de $C$. sempre como uma 'ramificação' bipartida de algo que estava estabelecido no momento anterior, as configurações que se tem difundido em geometrias de traços poderiam (ou deveriam), talvez, ser repensadas. Se há motivos para [士anterior] ser visto como operação secundária a partir do nó coronal, então, coronal e dorsal também poderiam ser vistos como operação secundária a partir do articulador língua. Caso contrário, porque não operar com 4 articuladores (por exemplo, labial, (pical, coronal e dorsal), em lugar de 3? E talvez 5, quando uma língua toma a posição dental como um ponto distinto de apical.

${ }^{23}$ Rangel (1998:135) observou, em 4 sujeitos, que "o contraste [vozl foi adquirido por último nas consoantes [dorsais]". 
1998:148). Mas, em Rangel (1998:136), o que se vê é um caso naquela direção e outro na direção oposta, o que leva a autora a observar: "ainda que ambas as substituições envolvam o traço [coronal]:[ \pm ant]". Outra conclusão possível, igualmente relevante, é que a aquisição do traço $[ \pm v o z]$ pode mostrar-se problemática e representar atraso no desenvolvimento fonológico de algumas crianças. Nesse caso, porém, o traço [ \pm contínuo] é adquirido, aparentemente sem empecilhos, antes daquele.

E, como chegamos até aqui, vamos dizer algo sobre a sequêencia da aquisição do sistema fonológico do Português. É conhecido o fato, confirmado pelos dados nos trabalhos mencionados (Rangel 1998:135; Mota 1997:31) que, das líquidas, / I / é a primeira a ser adquirida, chegando a ser usada para substituir todas as outras, em certo estágio. Mesmo assim, os mesmos dados mostram que / $1 /$ só se adquire após o estabelecimento das correlações coronal-dorsal, contínua-descontímua e vozeadodesvozeado (eventualmente antes dessa última, em crianças com 'desvios fonológicos').

Mota (1997:31) sugere que se trata, ao adquirir o / 1/, de adquirir o valor de traço [+aproximante] (lembrando que, para ela, o valor [-aproximante] seria parte da Raiz fornecida por GU). Não irei totalmente contra a idéia de que [+aprox] tenha um papel no surgimento de / / , mas quero sugerir que isso se deve justamente à 'entrada em cena' da correlação [ \pm contínuo]. Até então tínhamos, no sistema, em posição coronal, as possibilidades de produzir:

(i) uma obstruinte (isto é, [-soan]) não-aproximante [ $\mathrm{t}]$

(ii) uma soante não-aproximante $[\mathrm{n}]^{24}$.

Com a entrada da correlação [ \pm voz], o quadro ampliou-se, podendo produzir-se, além daquelas duas (a primeira delas, agora interpretada como obstruinte nãoaproximante desvozeada), também uma obstruinte não-aproximante vozeada $[\mathrm{d}]^{25}$.

Finalmente, entra em jogo a correlação contínua-descontínua. Reinterpretam-se, agora, as já existentes, para opor-se às novas produções. O resultado, na posição coronal fica sendo:

(i) uma obstruinte não-aproximante desvozeada descontínua: [ $\mathrm{t}$ ]

(ii) uma obstruinte não-aproximante vozeada descontínua: [ d ]

(iii) uma soante não-aproximante descontínua: $[\mathrm{n}]^{26}$

Porém, agora, a presença do traço [ \pm contínuo] permite surgir uma combinação antes inexistente e impossível:

(iv) uma soante aproximante descontínua: [1]

${ }^{24}$ Como observamos, uma socunte aproximante, com apenas tais traços (e ponto), marcava as vogais.

25 A outra possibilidade combinatória seria soante não-aproximante desvozeada, o que corresponde, obviamente, a uma näo-soante. Note-se que isso não pode ser confundido com o mecanismo, diferente, de produção de uma consoante nasal surda (como tenho demonstrado em D' Angelis 1998, vol.2:177-203).

${ }^{26}$ Insisto em lembrar que as soantes não participam da oposição [ \pm voz]. 
Nela, o traço descontínuo exige um gesto de obstrução no trato (o que é feito pela parte anterior da língua contra a região alveolar), mas o traço aproximante exige uma configuração oral que favoreça o vozeamento espontâneo. No caso da não-aproximante descontínua, o impedimento no trato oral deve ser total, e o vozeamento espontâneo só se obtém pelo abaixamento do véu palatino, nasalizando. No caso da aproximante descontínua, a soltura lateral ininterrupta garante vozeamento.

Mas, se é o estabelecimento do traço [ \pm contínuo] que permite as condições de surgimento da primeira líquida, o aparecimento desta deveria ser coetâneo com o surgimento das primeiras fricativas (que se opõe às plosivas por aquele mesmo traço). Se atentarmos aos dados presentes nos artigos com que este trabalho dialoga, parece que encontramos evidência favorável. Nos inventários iniciais (da pesquisa) nos sujeitos de Rangel (1998), apenas dois apresentam /1/. Desses dois, um deles apresenta também / $\mathrm{s} /$. Nos outros dois, a pesquisadora anota, para /1/, "realização que não alcançou o mínimo necessário para fazer parte do inventário: duas ocorrências em palavras diferentes". Nos mesmos sujeitos, para / s / ela registra: "sem possibilidade de ocorrência" (Rangel 1998:134). A propósito, adotando a geometria de traços de Clements \& Hume (1995), Rangel interpreta / / como distinto de / r / (que a criança adquire mais tarde) pela presença, no primeiro, da especificação [-contínuo] (ao lado das especificações [+soante, -vocálico, +aproximante] na Raiz, e [+voz] sob Laríngeo).

Se recorremos ao trabalho de Mota (1997), encontramos que a ausência de / s / e a ausência de / I / igualam-se em números absolutos entre os inventários dos seus 25 sujeitos (9 não possuíam / s / nem / 1 /). Se observamos os inventários dos sujeitos, um a um, analisando as relações entre a presença de $/ 1 /$ e a presença de fricativas (contínuas), verificamos que:

- 2 sujeitos não possuem nem /1/ nem fricativas nos seus inventários

- 3 sujeitos possuem / 1/, mas não possuem fricativas nos seus inventários $^{27}$

- 7 sujeitos possuem fricativas, mas não possuem / $1 /$ nos seus inventários ${ }^{28}$

- 13 sujeitos possuem tanto / / quanto fricativas nos seus inventários, sendo que 7 deles possuem todas as seis fricativa ${ }^{29}$

Os dados parecem mostrar duas coisas:

${ }_{28}^{27}$ Para um deles, alguma realização de / $\mathrm{v} /$ foi anotada.
${ }^{28}$ Dos sete, um tem apenas as fricativas $/ \mathrm{s} / \mathrm{e} / \mathrm{z} /(\mathrm{e}$ algo de $/ 3 /$ ); outros dois, possuem 4 fricativas (s, $z, \int, 3$ ) e os demais, 6 fricativas cada um. Além desses, outros 4 possuindo fricativas tem indicação de apresentar apenas alguma(s) realização(ões) de $/ 1 /$.

${ }^{29}$ Dos treze, sete possuem todas as seis fricativas e dois possuem quatro fricativas. Dos outros quatro. dois possuem / s / e / f / e algumas realizações de / z / (e. um deles, de / v /. o outro. de / 3 / ) e um possui / v , $\mathrm{z} / \mathrm{e}$ algumas realizações de / $\mathrm{f} /$. O último possui apenas $/ \mathrm{v} /$, mas para $/ / /$ de fato só consta alguma presença. 
(i) que tanto / / / como alguma fricativa podem aparecer primeiro, um em relação ao outro.

(ii) que a regra é as fricativas aparecerem primeiro (isto é, antes de /1/).

A proposta de Mota (1997:31) é que /1/ aparece depois das fricativas (contínuas) labiais e coronais anteriores. Observo, porém, que a própria pesquisadora reconhece haver situações em que a criança, passando ao reconhecimento de duas correlações distintas, encontra "dificuldade em lidar com dois traços marcados ao mesmo tempo e portanto escolhe um caminho ou outro" (Mota 1997:38). Ainda que não trabalhando com a mesma perspectiva (de aquisição de valores marcados apenas), aceito a possibilidade de, em certos casos, algumas crianças realizarem um percurso, e outras realizarem percurso alternativo. É o que sugiro para interpretar os dados acima para o caso de $/ 1 /$ e $/$ fricativas/, como fruto da consolidação da oposição contínuodescontínuo.

Não surpreende, na sequiência, a observação de Rangel (1998:135) de que " $a$ segunda líquida a fazer parte do sistema fonológico dos informantes foi a dorsal / $R /$ ". Não surpreende em razão da análise que hoje podemos fazer do Português. Como tenho observado, em uma nota de rodapé mais acima, a análise do Português por Mattoso Câmara conta já mais de 40 anos. No tocante às chamadas "vibrantes", em seu tempo dava-se uma oposição identificada como vibrante simples x vibrante múltipla, ainda que Mattoso observasse a ampla variação que já se mostrava na realização do "erre forte". Eis sua descrição de então:

\begin{abstract}
"Já nas vibrantes a língua vibra, quer num só golpe junto aos dentes superiores, para / r' brando, quer, para o / $r /$ forte, em golpes miltiplos junto alos dentes superiores, ou em vibrações da parte dorsal jumto ao véu palatino. ou en vez da lingua há a vibração da ívula. ou se dí além do fundo da boca propriamente dita uma friç̧ũo faríngea" (Câmara Jr. [1970] 1991:49).
\end{abstract}

Ainda que variações dialetais persistam, certamente para todos os casos referidos por Mattoso, defendo que, no Português brasileiro atual, na variedade chamada 'padrão' ou 'urbana', a oposição entre $/ r /$ brando e $/ R /$ forte vem sendo re-interpretada para integrar-se à correlação opositiva mais produtiva na língua, ou seja, fazer-se oposição entre soante e obstruinte. Desse modo, o chamado $/ R /$ forte é hoje, na maioria dos casos, uma obstruinte contínua (fricativa), realizada em geral como velar (isto é, dorsal $=[\mathrm{x}]$ ) e, em muitos casos, como glotal $=[\mathrm{h}]^{30}$. Assim, uma vez estabelecida a correlação contínua-descontínua na língua, a criança em aquisição explora as

${ }^{30}$ Pesquisa sobre aquisição de liquidas não-laterais em poituguês, por Ana Ruth Miranda, mostrou que, em fase de aquisição, na substituição de 'r-forte', "pôde-se observar que há ocorrência de consoantes plosivas". Para a pesquisadora, isso "demonstra que um grupo de informantes estava tratando a rótica como uma plosiva velar, ou seja, como um segmento cujo grau de soância é zero" (Miranda 1998:129). Não assumo, como seria previsivel, as interpretações da pesquisadora com base em uma Escala de Soância de valor fonológico, seja porque, de um lado, escalas de sonância só podem ter valor empírico, seja, por outro, porque tais escalas só podem ter sentido em fonologia numa abordagem que reconheça valor nas imposições fonéticas, mas não em uma abordagem enı que a fonologia é absolutamente autônoma, como naquela que orienta as referidas interpretações. 
possibilidades que a língua apresenta (via input) que sejam mais favoráveis, isto é, mais próximas dos traços ou pontos sobre os quais tenha maior controle. Desse modo, entre / $1 /$ coronal (descontínua) e / R/ dorsal (contínua), o primeiro alvo é mais facilmente atingível pela criança. Mas, depois dele, um $/ R /$ forte é, pelas razões indicadas, o melhor candidato a emergir, ante que um $/ r /$ brando. ${ }^{31}$

Nos inventários fonológicos dos sujeitos da pesquisa de Mota (1997:28) de fato encontramos alguns casos com realizações de $/ R /$ forte antes de $/ r /$ brando, mas na maior parte dos casos o $/ \mathrm{r} /$ brando aparece primeiro (dos 12 casos em que comparecem 'vibrantes', em 6 deles $/ r /$ brando é produzido antes que $/ R /$ forte). Há, no entanto, a limitação no número da amostra, e o fato de tratar-se de crianças consideradas "com problemas na aquisição da fonologia do português" (Mota 1997:23).

Não haveria como optar, aqui, entre os resultados de Rangel e os de Mota (esta coloca $/ R /$ forte como o último fonema consonantal a ser adquirido, interpretando-o como a combinação difícil de três 'traços marcados': [+aprox, +cont, dors] ). Felizmente, podemos contar com um estudo específico da aquisição de líquidas nãolaterais no Português, conduzido por Ana Ruth Miranda (1998). Tendo como base dados de aquisição de 110 crianças (55 meninos e 55 meninas, divididos em 11 faixas etárias entre 2 anos e 3 anos e 9 meses), Miranda apresenta conclusões categóricas indicando a aquisição de $/ R /$ forte antes de $/ r /$ fraco. Comentando um gráfico da produção de cada uma das modalidades de 'erre' nas onze faixas etárias da pesquisa, Miranda (1998:126) registra:

\begin{abstract}
"Pode-se observar que a aquisiçäo de 'r-forte', mesmo aos 2 anos (fx 1), atinge índices que só serão alcançados para 'r-fraco' pelas crianças de 3:2 anos ( $f x$ 8). Segundo o critério adotado, que considera o índice de $75 \%$ c p,p a expressão de que o segmento está adquirido. mesmo que ainda não estabilizado, pode-se dizer que a partir da faixa 4 o 'r-forte' está adquirido; o mesmo só é possível afirmar em relação ao 'r-fraco' nos dados pertencentes à faixa 11 ".32
\end{abstract}

Observemos, agora, o caminho alternativo que Rangel e Mota sugerem para a aquisição das líquidas. Rangel, como vimos, observou primeiro o surgimento de $/ R /$ forte $\mathrm{e}$, a seguir, sem indicar ordem entre eles, / $\mathrm{K} / \mathrm{e} / \mathrm{f} /$. Mota, por sua vez, parece propor que entre a lateral palatal $/ K /$ e o tepe $/ \mathrm{s} /$ não exista ordenamento, uma vez que, para ambos, tratar-se-ia de adquirir "2 traços marcados" (cf. Mota 1997:31). Os inventários fonológicos que apresenta, no entanto, atestam seis casos de aparecimento de vibrante antes de lateral palatal, e apenas um caso de surgimento dessa lateral antes que se registrasse qualquer dos 'erres'.

Assumimos que a distinção fonológica entre / $1 /$ e / i / se faz pelo traço [ \pm contínuo]. Essa é também a posição adotada por Rangel (1998:137), e o que expressa Mota na seguinte passagem:

${ }^{31}$ Se a variante familiar for glotal, é possivel que sua aquisição seja demorada em relação a / 1 / e, eventualmente, isso poderia explicar sua aquisição posterior a $/ \mathrm{r} /$ brando em alguns casos.

${ }^{32}$ Sendo 11 faixas etárias para idades variando de 2 anos a 3 anos e nove meses (total: 22 meses). concluímos que a faixa 4 corresponde a crianças com 2 anos e seis e 2 anos e sete meses, e a faixa 11 a crianças com 3 anos e seis e 3 anos e sete meses. 
"O traço [+continuo] é especificado primeiro na classe das obstruintes, que é menos marcada e depois na classe das líquidas que é mais marcada. Assim, se um sistema tem / $\mathrm{r} / 0 u / R /$ deverá ter também pelo menos uma fricativa" (Mota 1997:35).

Sendo assim, uma vez construída a oposição contínuo-descontínuo, como já se disse, ela passa a ficar disponível para as combinações também com soante e aproximante. Já indiquei como disso pode resultar /1/. Que o tepe / $/$ / seja resultado de uma das novas possibilidades combinatórias, também é compreensível. Nesse caso, / r / resulta da combinação de traços [+soan,+aprox,+cont]. Aparentemente isso pode ser confundido com vogal (no caso de abolirmos o traço vocóide colocado ad hoc, atado ao nó Raiz, por Clements $1990^{33}$ ) e, talvez, não seja sem razão que haja dialetos do Português que possam admiti-lo no núcleo silábico, em razão da pauta prosódica ${ }^{34}$.

De fato, parece que algum reconhecimento é construído, em algum momento, na fonologia da criança, do que sejam elementos passíveis de compor núcleo silábico, em oposição aos que só podem marginá-lo. Não me parece defensável, no entanto, supor que esse tipo de distinção venha marcada, metafisicamente, em uma Raiz esotérica da GU, sem qualquer motivação na experiência sensorial da criança. Pode-se sugerir que, enquanto o tipo silábico básico $\mathbf{C V}$ é o único na produção da criança, ele corresponde a uma alternância fisio-mecânica dos gestos de "fechar" e "abrir" a mandíbula. A construção de sílabas do tipo $\mathbf{V}$, ou CVC, ou ambas (a depender do padrão silábico da língua alvo) seria o momento em que a criança estabelece, com base no input, ou uma "escala de sonoridade", ou uma delimitação empírica de Vs e Cs, marcando-os com um traço distintivo novo: digamos, o velho [silábico] (ou o [vocóide] de Clements, tanto faz, uma vez que o mecanismo desse estabelecimento é que está por ser investigado).

Dito isso, retornamos à questão da interpretação de / $\mathrm{f} /$. Estando já definido o grupo de segmentos capazes de integrar núcleo silábico (marcados, eventualmente, por uma correlação estabelecida por um traço como [ $₫$ silábico] ou outro), o aparecimento de / f / se dá concomitante ao seu reconhecimento como participante de margem silábica (a esta altura, uma posição já integrante da fonologia da criança). A propósito, / f / comparece, primeiro, na rima silábica, que é a posição mais próxima do núcleo vocálico e a mais propícia para elementos [+aprox,+soan]. Somente em momento posterior é que I s / ocupará o lugar dos onsets onde vinha sendo substituído por / / / e, finalmente, quando a criança adquira um padrão silábico com onset complexo (tipo $\underline{\mathrm{CCVC}}$ ) o tepe poderá aparecer também na segunda posição desse tipo de onset. ${ }^{35}$

Quanto à precedência de / $1 /$ sobre / / /, alguma palavra precisa ser dita. Em D’Angelis 1998 discorro sobre as características fonéticas que aproximam e que

33 Para a crítica dessa proposição de Clements, assumida em Clements \& Hume 1995, veja-se D'Angelis 1998, vol I:100ss.

${ }^{34} \mathrm{O}$ caso que nos vem à mente, de imediato, é do Português europeu que, por conta de seu padrão acentual distinto, costuma realizar pronúncias como: [apr'tadu], [1 amodrniza'sãw] , etc.

35 Isso também é confirmado pelo estudo de Miranda (1998:127-8): "a análise não pôde ignorar que nos dados da coda final a produção da rótica foi muito precoce, sendo essa a posição em que o 'r-fraco' começou a ser produzido pelas crianças". 
separam essas duas líquidas (que, em muitas línguas, são variantes condicionadas de um mesmo fonema). Cito ali Catford, que justifica como podemos ter uma percepção fácil de elementos como [r], que se constituem de "articulações essencialmente momentâneas". A primeira razão, lembra ele, é o fato de elas operarem como "unidades fonêmicas" na língua. "A segunda razão, prossegue ele - foneticamente mais interessante, é que estamos acostumados a perceber como segmentos todos os estados articulatórios (ou quase-estados) flanqueados por uma transição de aproximação (onglide) e uma transição de afastamento (off-glide): e isso ainda opera bem, mesmo quando o período quase estável interveniente é reduzido a zero" (Catford 1977:228). E sobre suas caraterísticas distintivas, Kent \& Read (1992:139) apontam para fatores temporais: "uma porçâo estável e as durações da transição de Fl variam de um padrão I $r /($ periodo estável curto e transição longa) a um padrão / I/(periodo estável longo e transição curta)". Essa diferença certamente coloca / 1/ como elemento de mais fácil realização que $/ \mathrm{r} /$, porque este último exige um controle mais fino (ou, mais acurado) do articulador ativo. ${ }^{36}$

Finalmente, em um momento posterior ao estabelecimento da distinção coronaldorsal, e igualmente posterior ao surgimento das oposições contínuo-descontínuo e vozeado-desvozeado, a criança explorará uma nova possibilidade de ponto articulador, 'desdobrando' coronal em [+anterior] e [-anterior]. Os dados mostram que a soante descontinua [ $\mathrm{n}$ ] ocorre antes que as obstruintes contínuas [ $\left.\int\right] \mathrm{e}[3] \mathrm{em}$ Português e, conforme também conclui Mota (1997:31), estas últimas aparecem antes que uma soante descontínua aproximante coronal não-anterior, ou seja, antes de $[\kappa]$.

\section{CONCLUSÃO}

Como vimos, a noção de 'traço marcado' orienta a perspectiva interpretativa de Mota. Ela sugere que a GU fornece à criança uma primeira estrutura (uma "geometria básica") que seria "composta apenas por traços não-marcados" (Mota 1997:31). O processo de aquisição da fonologia da língua consistiria em complexificar, pouco a pouco, essa geometria, pelo acréscimo a ela, de um traço marcado a cada vez.

$\mathrm{O}$ que se deve questionar é quem marcou o traço marcado. No caso, parece estarmos diante de um fato metafísico: algo que legamos das outras gerações geneticamente, via GU. Não será possível pensar em uma circularidade nisso? Em lugar

${ }^{36}$ Cf. D'Angelis 1998,vol.11:325-326. Este texto estava pronto quando tive oportunidade de discutir o problema das análises fonológicas para as líquidas, e para os róticos em particular, com Adelaide Silva (professora da UFPr e pesquisadora do LAFAPE-IEL-Unicamp). Tendo se ocupado da descrição fonéticoacústica das líquidas do Português Brasileiro (cf. Silva 1996), ela observa que a diferença duracional. apontada por Kent \& Read, não é a única nem a principal pista acústica para diferenciar esses sons, mas que a frequiência dos formantes joga papel decisivo na distinção de /// e / r/. Ademais. lembra ela, as observações de Kent \& Read dizem respeito ao Inglês, e não seriam universais (Silva - comunicação pessoal). O outro ponto em que Silva discorda é da caracterização de /// como descontínua, na esteira da "velha proposta de SPE". Sugere, ao contrário. sua caracterização como [+contínua], o que já é parte de sua tese de doutorado. em andamento. De todo modo, é inegável o "complicador" articulatório que /r/ apresenta em relação a $/ 1 /$. 
de dizer, por exemplo, que obstruintes surdas - ou, [-soan, -voz] - são as primeiras e as mais comuns nas línguas porque são não-marcadas, não é possível dizer que obstruintes surdas são não-marcadas porque são as primeiras e as mais comuns nas línguas? Dizendo de uma forma, ainda mais clara: será que determinadas articulações ou combinações de gestos articulatórios são muito comuns porque são não-marcadas, ou são não-marcadas porque são particularmente simples e facilmente combináveis, o que as torna muito comuns nas línguas?

O que se coloca em questão, enfim, é o que isso tudo nos explica sobre a fonologia das línguas? Dizer que o traço coronal [-anterior] é mais marcado em relação ao traço dorsal é diferente - ou de alguma forma é mais explicativo - do que dizer que constatamos empiricamente que as crianças brasileiras adquirem o traço dorsal antes que coronal [-anterior] ? Estou seriamente convencido de que a resposta a essa pergunta é francamente negativa se acreditarmos que não-marcado é um "F-DNA", ou seja, parte de um DNA fonológico do segmento (ou, de nós mesmos), herança contida na GU. Isso quer dizer que a arbitrariedade da marcação 'divina' de certos traços torna as duas formulações redundantes e absolutamente circulares. Em outras palavras, a primeira das duas formulações só pode ser, efetivamente (e não, apenas formalmente), diferente da segunda, em uma perspectiva como a adotada aqui, pela qual marcação é uma decorrência do processo de construção/aquisição da fonologia e que guarda, por isso, duas características:

- um traço só é ou pode ser marcado em relação a seu valor oposto, ou a outro traço, e vice-versa: um traço só pode ser não-marcado em relação a seu valor oposto, ou a outro traço. Não existe o valor não-marcado in absolute ${ }^{37}$.

- um traço não-marcado corresponde, dentro de um sistema lingüístico, a uma característica já presente de forma permanente na produção lingüística do sujeito antes que ela tenha ganhado valor lingüístico. ${ }^{38}$

Em resumo, sugeri aqui outra abordagem da fonologia, pela qual a noção de $n \tilde{a} o$. marcado é decorrente do reconhecimento/estabelecimento de uma correlação opositiva.

37 Imagine-se um sujeito que mora em uma comunidade rural, falante de um dialeto que não é certamente o chamado "dialeto padrão". Digamos que seja encaminhado, aos 6 ou 7 anos completos, para estudar na cidade (essa foi uma experiência muito comum, por exemplo, no sul do Brasil, com crianças enviadas aos seminários católicos). Esse será,possivelmente, o momento em que esse sujeito se dará conta de muitas diferenças entre o seu falar e o falar de outras pessoas (digamos, seus professores). E terá mesmo a sua atenção explicitamente chamada para isso, pela correção em um ensino normativo. Até então. ele falava, simplesmente. Somente a partir dessa experiência contrastiva é que esse sujeito construirá uma noção de fala marcada x não-marcada. A marcada, para ele, certamente será a 'nova' fala que será obrigado a produzir no ambiente escolar (que apresentará dificuldades onde a sua fala - 'antiga'- jamais lhe custou, da fonologia à sintaxe). Para seus professores, ao contrário, a fala dele será tomada por marcada, ainda que jamais ela se coloque, para eles, como um objetivo de aprendizagem. Mas será marcada em relação à outra, considerada "a língua", esta outra que, a partir do confronto com as formas não-padrão, passa a ser entendida como a forma "correta" de falar.

${ }^{38}$ Há muitas implicações lógicas dessa posição. Uma, por exemplo, é reconhecer o fato de que, para certos falantes, coronal [-anterior] é traço não-marcado em relação a coronal [+anterior] em fricativas. Essa perspectiva explica, também, que formas verbais irregulares como "fiz" e "sotibe" sejam marcudus em relação ao paradigma anteriormente fixxado pelo falante para os demais verbos da mesma conjugação. 
O falante sempre tomará como menos complexa a realização que já era capaz de produzir antes do reconhecimento daquela oposição fonológica ${ }^{39}$.

Partindo dessas concepções, busco justificar certas 'escolhas' prévias ao estabelecimento de determinadas correlações opositivas como condicionamentos fonéticos ou, talvez melhor dizendo, como imposições das limitações no controle, pelo falante, de parte do seu aparelho fonador ${ }^{40}$. A perspectiva deve poder abarcar, sem qualquer dificuldade, também os estágios de aquisição em línguas de sinais.

Enfim, reunir e confrontar descobertas presentes em cuidadosos estudos longitudinais e comparativos de aquisição (confrontando, inclusive, aquisição 'normal' e com 'desvios'), com princípios de uma abordagem fonológica que preza a investigação fonética e assume a possibilidade de se construir uma representação adequada das relações inter-traços fonológicos parece ser um caminho desafiador e promissor para a abertura de novos horizontes na teoria fonológica e na interpretação do Português, em particular.

\section{REFERÊNCIAS BIBLIOGRÁFICAS}

ALBANO, Eleonora (1990). Da falla à linguatagem - tocando de ouvido. São Paulo: Martins Fontes.

CÂMARA Jr., Joaquim M. (1991). A estruturu da língua portuguescu. (20ª ed.) Petrópolis: Vozes.

CATFORD, J.C. (1977). Fundamental problems in phonetics. Edinburgh: Edinburgh University Press.

CLEMENTS, G.N. (1987). Phonological feature representation and the description of intrusive stops. In A. Bosch et al. (eds.). Parasession on Autosegmental and Metrical Phonology. Chicago: Chicago Linguistic Society, pp. 29-50.

. (1990). The role of sonority cycle in core syllabification. In J. Kingston \& M.E. Beckman (eds.). Papers in Laboratory Phonology l: between the grammar and phusics of speech. Cambridge/UK: Cambridge University Press. pp. 283-333.

CLEMENTS, G.N. \& HUME. E. (1995). The internal organization os speech sounds. In J. Goldsmith (ed.). The handbook of phonological theory. Massachusetts: Blackwell, pp. 245-306.

D’ANGELIS, Wilmar da Rocha (1998). Traços de modo e modos de traçar geometrias: língutas Macro-Jê \& teoria fonológica. Tese de Doutorado, 2 vols. Campinas: IEL-UNICAMP.

DE LEMOS, Cláudia T.G. (1997). Native speaker’s intuitions and metalinguistic abilities: what do they have in common from the point of view of language acquisition? Cadernos de Estudos Lingüisticos. Campinas: IEL-UNICAMP, $\mathrm{n}^{\circ} 33, \mathrm{pp} .5-14$.

39 Quem, efetivamente, identifica e define conscientemente um valor como não-marcudo são lingüistas (embora, alguns sejam capazes de postulaçôes bastante anti-intuitivas, para salvar modelos teóricos com que trabalham). Um falante opera com essa noção apenas inconscientemente (por exemplo, quando regras morfofonológicas requerem alguma inserção epentética para atendimento a padrões silábicos ou prosódicos mais complexos).

${ }^{40}$ Não deixando de notar, com Albano (1990:102), que "grande parte da tarefa dos estudiosos da fonologia infantil na última década consistiu em demonstrar que as crianças têm um longo camínho a percorrer antes de dominar contrastes segmentais do tipo jakobsoniano". 
FRONZA, Cátia de A. (1998). O domínio do traço [ \pm sonoro] e do nó ponto de C na aquisição normal e com desvios da fonologia do português brasileiro. Letrus de Hoje, Porto Alegre, vol. 33, n. 2, pp. 141-150.

KENT, Ray D. \& READ, Charles (1992). The acoustic analysis of speech. San Diego/CA: Singular Publishing Group.

LEITE, Yonne. (1990). O pensamento fonológico de J. Mattoso Câmara Jr. Lingutagem: Revista Brusileira de Estudos de Lingut e Literutura. Rio de Janeiro: Presença, $\mathrm{n}^{\circ}$ 7: 33-38.

MIRANDA, Ana Ruth M. (1998). A aquisição das líquidas não-laterais no português do Brasil. Letrus de Hoje, Porto Alegre, vol. 33, n. 2, pp.123-131.

MOTA, Helena Bolli (1997). Aquisição segmental do Português: um modelo implicacional de complexidade de traços. Letras de Hoje. Porto Alegre, vol. 32, n. 4, pp.23-47.

PIGGOTT, G. L. (1992). Variability in feature dependency: the case of nasality. Natural Lantuatge and Linguistic Theory, 10: 33-77.

RANGEL, G.A. (1998). Os diferentes caminhos percorridos na aquisição da fonologia do português. Letras de Hoje. Porto Alegre, vol. 33, n. 2, pp.133-140.

SAGEY, Elizabeth Caroline. (1986). The representation of features and relations in non-linear phonology. PhD Dissertation. Cambridge/MA: MIT.

SiLVA, Adelaide H. Pescatori. (1996). Para a descrijão fonético-acuística das líquidas no português brasileiro: dados de um informante paulistano. Campinas: IEL-Unicamp. Dissertação de Mestrado, inédita.

TRUBETZKOY, Nikolay. (1969). Principles of Phonology. Trad. C.A.M. Baltaxe. Berkeley, Los Angeles: University of California Press. (Publicação original, pelo Círculo Linguístico de Praga, em alemão: 1939). 